\title{
Medical students' perspectives about the traditional and the integrated learning programs in the college of medicine- University of Bisha
}

Ayman Mohamed Alashkar ( $\sim$ aymanpara@yahoo.com )

College of medicine, University of Bisha, KSA- Faculty of medicine, Ain Shams University, Cairo, Egypt. https://orcid.org/0000-0003-4815-8731

Abdullah Abdelazim Hashish

College of medicine, University of Bisha, KSA https://orcid.org/0000-0003-1531-3918

Adel Aborgela

College of medicine, University of Bisha, KSA

Ashraf Salah Metwally

College of medicine, University of Bisha, KSA https://orcid.org/0000-0002-4548-0357

Hany Sonpol

College of medicine, University of Bisha, KSA https://orcid.org/0000-0002-8031-3765

Ahmed Sinbel

College of medicine, University of Bisha, KSA https://orcid.org/0000-0003-4178-2988

Mushabab Al-Ghamdi

College of medicine, University of Bisha, KSA https://orcid.org/0000-0002-8675-5871

Research Article

Keywords: Traditional, integrated, learning program

Posted Date: June 8th, 2020

DOI: https://doi.org/10.21203/rs.3.rs-33971/v1

License: (c) (i) This work is licensed under a Creative Commons Attribution 4.0 International License. Read Full License 


\section{Abstract}

Purpose: Students' approaches to learning are central to the process of learning. There is strong debate about the efficiency of traditional learning program (TLP) and the integrated learning program (ILP) in medical schools. TLP is easy for the students being passive learners and for the tutors playing the role of sage on the stage. ILP is mainly student centered in which the students are active learners with mentoring of their tutors. It is important to know the perspectives of medical school students about both programs as they used to apply TLP in the $1^{\text {st }}$ year and starting ILP from the $2^{\text {nd }}$ year.

Methodology: This study adopted quantitative research methodology. We addressed the 2nd and 3rd year medical students. Online survey using the Google forms was applied for data collection.

Results: agreement of the integrated program (80.8\%) exceeded the traditional (48.5\%) especially in improving the communication skills, dealing with new technologies, reinforcement of competencies in the research field, and to less extent for its suitability to be applied in medical schools nowadays, development of desired doctor skills to deal with patients and for provision of good approach for medical practice, and lastly for its suitability to identify and deal with the community needs. There was no statistical significance between both programs regarding support of professionalism values. The disagreement of ILP (19.2\%) was much lower than TLP (51.5\%).

Conclusion: Integrated learning program becomes an innovative tool for learning in medical schools with very good compliance among the medical students.

\section{Introduction}

Knowledge and skills transfer are the role of any education system and educational institutes are important tools for achieving social goals [1]. Students' approaches to learning are milestones for the learning process. There is clue that how students perceive the learning environment has a great impact on the learning approaches. Nevertheless, the relation between the learning environment, the way in which it is perceived by students and students' learning approaches is not clear [2].

Nearly all medical and pharmaceutical education schools around the world were adopting the Lecture-based, teacher-centered traditional pedagogy [3]. This approach relies mainly on rote learning of the basic science subjects in order to pass the exams. This approach gives little or no attention to the practical applications of the gained knowledge. Little interaction in the traditional lectures decreases the students' attention and engagement with inside the classroom [4]. The passive learning methods are not only lectures but also reading, audiovisuals and demonstrations as well [5]. Forgetting the basic knowledge by learners in clinical years is one of the major shortcomings of the traditional learning program (TLP) [6].

In contrast, the competency based curriculum involves students`engagement in different learning activities which enhances the development of Bloom's higher order cognitive skills $[7,8]$. Problem-based learning (PBL), case-based learning (CBL), and team based learning (TBL) are examples of active learning approaches [9]. The active integrated learning program (ILP) becomes the preferable approach for the faculty and the medical school administrators as it engages the students in small group working to solve real world cases or problems. This will stimulate the higher order skills (HOS) of the students like analysis, synthesis, evaluation, and application. This will ensure better collaboration of the basic science knowledge and the clinical application of such knowledge to build the desired future physician [10].

Although there is high student engagement in the active learning approach, yet there is still contradiction about it. The University of Virginia apply the active learning approach in the preclinical year but the official reports denoted that many students didn taendtheseactivitieswithotherstudentsexperiencedp $\infty$ raentionwhenaend $\in$ gtheses. Manystudents $\in$ dicatedttheirbe $\neq$ fitso $m$ the $\leq$ arn $\in$ gi feedback about the active learning approach as some students reported feeling of poor preparedness when participating in PBL-based curricula, another studies showed the students reported increased confidence, improved communication skills, greater interaction between classmates, and improved clinical reasoning and decision making by the active learning but on the other hand the students reported negative attitude towards $\mathrm{CBL}$ as it requires them to spend much more time and efforts to reach the desired knowledge with no belief that CBL prepares them well for exams [14]. In addition to the previous studies, some medical education literatures failed to find the positive effect of the active learning on the exam score $[15,16]$.

So, this study aimed to evaluate medical students ' perspectives about the traditional and the integrated learning programs in the college of medicineUniversity of Bisha - KSA

\section{Aim of the work}

Evaluation of medical students` perspectives about the traditional and the integrated learning programs.

\section{Subjects And Methods 1. The subjects}

Sample size was 82 students. The inclusion criterion included the $2^{\text {nd }}$ and $3^{\text {rd }}$ year medical students who agreed to participate in the study and the exclusion criterion were the $2^{\text {nd }}$ and $3^{\text {rd }}$ year medical students who refuse to participate. All the $2^{\text {nd }}$ and $3^{\text {rd }}$ year medical students were invited to share in this study. An 


\section{The methods}

Online survey was done for the 2nd and 3rd year medical students in UBCOM. This includes detailed questionnaire about both of traditional and integrated programs in the college of medicine, University of Bisha. The questionnaire was exposed to a validation procedure that included its perusal by medical students, interns, and experts in the medical education field. The questionnaire was checked for item appropriateness and comprehensiveness (face and content validity). A five-point Likert scale ( $0=$ strongly disagree; $4=$ strongly agree) was adopted within the questionnaires.

\section{The study design}

Quantitative research

\section{The statistical methods used}

The collected data were computerized and statistically analyzed using Graph Pad Prism 5.01.Chi-square test that was used to compare the qualitative variables between groups. $P$ values less than 0.05 was considered statistically significant.

\section{Ethical considerations}

Ethical approval: obtained from the ethical committee of the college of medicine- University of Bisha "UBCOM/H-06-BH-087 (4/17)". The permission was taken from the Institution research board. An agreement of the students to be enrolled was considered as informed consent.

\section{Results}

The total student's population targeted was 82 students with 55 responding (67\%).

The students' responses were $15.5 \%, 26.4 \%$ strongly agree, $21.6 \%, 37.7 \%$ agree, $9.1 \%, 7.5 \%$ strongly disagree, and $30.2 \%, 7.7 \%$ disagree about different learning parameters established by TLP and ILP respectively (fig. $1 \mathrm{~A}$ ).

Collectively, agreement of the ILP exceeded the TLP and disagreement of the ILP was much lower than the traditional one as described in (fig. 1 B).

(Total responses in traditional program and integrated program are 336 and 349 consecutively). The neutral stage of satisfaction was excluded to avoid bias in the results. Summation of agree and strongly agree results was considered agreement, as well as the results of disagree plus strongly disagree were summated as disagreement (Details in supplementary file).

The ILP showed trustfulness among the medical students rather than the TLP. They mainly agreed with ILP in improving the communication skills, dealing with new technologies, reinforcement of competencies in the research field with percentages $69.1 \%, 63.6 \%$, and $65.5 \%$ respectively compared to $27.9 \%, 38.2 \%$, and $25.4 \%$ respectively for TLP with high statistically significant difference between the 2 programs (table1, fig. 2, 3, 4, 5).

Table (1): Summation and comparison of student consideration after exclusion of the neutral degree of satisfaction

\begin{tabular}{|l|c|c|c|c|}
\hline \multicolumn{1}{|c|}{ Topic } & Agreement & Disagreement & Total & P value \\
\hline Suitable for medical colleges nowadays & $22(33)$ & $25(8)$ & $47(41)$ & $\begin{array}{c}0.0011 \\
* *\end{array}$ \\
\hline Suitable to identify and deal with the community needs & $27(34)$ & $20(9)$ & $47(43)$ & $\begin{array}{c}0.0416 \\
*\end{array}$ \\
\hline Improves communication skills & $17(38)$ & $26(8)$ & $43(46)$ & $\begin{array}{c}<0.0001 \\
* * *\end{array}$ \\
\hline Reinforces competencies in the research field & $14(36)$ & $21(9)$ & $35(45)$ & $\begin{array}{c}0.0004 \\
* * *\end{array}$ \\
\hline Improves skills in dealing with new technologies & $21(35)$ & $28(7)$ & $49(42)$ & $\begin{array}{c}<0.0001 \\
* * *\end{array}$ \\
\hline Support professionalism & $20(28)$ & $15(10)$ & $35(38)$ & $\begin{array}{c}0.1492 \\
n s\end{array}$ \\
\hline Has a good approach to medical practice & $21(37)$ & $18(8)$ & $39(45)$ & $\begin{array}{c}0.0086 \\
* *\end{array}$ \\
\hline Develops the desired doctor skills to deal with patients & $21(41)$ & $20(8)$ & $41(49)$ & 0.0013 \\
$* *$
\end{tabular}

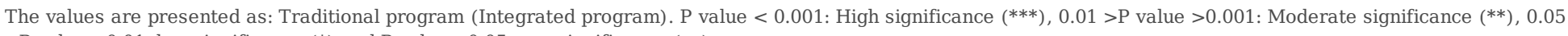
$>$ P value $>0.01$ : low significance $(*)$ and $\mathrm{P}$ value $>0.05$ : non significance (ns)

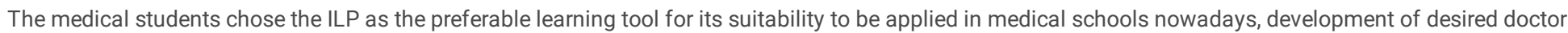

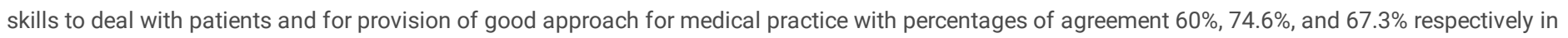
contrast to $30 \%, 28.5 \%$, and $38.2 \%$ respectively TLP with moderate significant difference between the 2 programs (table 1 , fig. 2 , 3 , 4,5 ). 
Suitability to identify and deal with the community needs parameter was selected by the medical students to be reinforced by the ILP outcome with $61.8 \%$ agreement; however $49.1 \%$ select the TLP to reinforce that parameter with low significant difference between both programs (table 1, fig. 2, 4).

Professionalism is the only learning parameter that showed no significant statistical difference between both of the learning programs. $50.9 \%$ considered the ILP capable of establishing such value while, $36.3 \%$ considered the TLP is the capable one (table 1 , fig. 3,5 ).

\section{Discussion}

The Legacy curriculum relied mainly on lecture-based approach, rote learning with few activities $[17,18]$.

New approaches in medical education adopt self regulated learning (SRL), learn by doing and small group problem solving in order to stimulate the higher cognitive skills of the medical students to prepare them to be the future professional physicians [19]. Nevertheless, some other researchers believed that ILP may or may not lead to learning enhancement in students [20].

Studies reach a consensus that the main influence of the students $\leq$ arn $\in$ gisthestudents perception of the educational context rather than the context itself $[21,22]$.

So, this study results may help the medical education specialist to know more regarding the students` perspectives about the TLP and ILP.

The medical students chose ILP to be more effective than the TLP in improving their communication skills, dealing with new technologies and reinforcement of competencies in the research field with high statistically significant difference between the 2 programs. This concur with reports described the positive effects of ILP on development of good communication skills to deal with peers, and instructors [23,24]. This is in congruence with a review study that revealed the importance of new technologies in the conduction of the ILP activities like PBL [25]. The study results agreed with studies that revealed the importance of ILP to develop a future physician and researcher [26, 27].

The study revealed that ILP was the preferable learning tool for medical students due to its suitability to be applied in medical schools nowadays, development of desired doctor skills to deal with patients and for provision of good approach to medical practice. This is agreed by the study about the ILP stated that discussion groups, active participation in different learning activities and collaboration with classmates and teachers resulted in a higher retention of learning [5]. Another authors proved that gaining clinical skills and retention of knowledge are achieved by removing the barrier between basic and clinical sciences. Physicians having the updated knowledge, desired clinical skills and professional behavior are the needs of today's environment [6].

Suitability to identify and deal with the community needs parameter was selected by the medical students to be reinforced by the ILP with $61.8 \%$ agreement; however $49.1 \%$ select the TLP to reinforce that parameter with low significant difference. This is concurs with some authors who have described ILP to have about 6 hrs per week for seminars of clinical skills training and community dimensions related to medical practice [28].

Professionalism is the only learning parameter that showed no significant statistical difference between both of the learning programs. This reflects the value and the great importance of professionalism to be an important component in any learning program. Reports revealed that medical schools, residency programs and hospitals have hidden curricula for behavior, ethics and professionalism. Positive role models support the values and characters of professional physician while negative ones contradict with the community and patient care values [29].

The transition from TLP to ILP has many important challenges to both students and faculty in medical schools [30] Deficiency of curriculum specialists and poor infrastructure prevents the transformation from TLP to ILP [16].

\section{Conclusion}

ILP become the more suitable innovative tool for learning in medical schools with very good compliance among the medical students regarding development of communication skills, dealing with new technologies, research competencies, desired doctor skills to deal with patients with doctor`s good approach to medical practice, identification and dealing with community needs in addition to raising the values of professionalism.

\section{Declarations}

Acknowledgements: None.

\section{Funding: None}

Conflicts of interest: We wish to confirm that there are no known conflicts of interest associated with this publication. We confirm that the manuscript has been read and approved by all named authors and that there are no other persons who satisfied the criteria for authorship but are not listed. We further confirm that the order of authors listed in the manuscript has been approved by all of us.

Author contribution: design of the work: Adel Aboregela; data analysis and interpretation: Ayman Al-Ashkar and Hany Sonpol; drafting the article: Ayman AlAshkar and Abdullah Hashish; critical revision of the article: Ashraf Salah and Ahmed Sinbel; completion of the article: Mushabab El-Ghamdi; and final approval of the version to be published: all authors.

\section{References}

Loading [MathJax]/jax/output/CommonHTML/fonts/TeX/fontdata.js 
1. Safi A. Education in elementary, junior high school, and senior high school levels. 10th Edition, Tehran; 2009. SAMT Publications.

2. Marton F, Säljö R. On qualitative differences in learning: I-Outcome and process British. J Educ Psychol. 1976;46(1):4-11

3. Islam MA, Khan SA, Talukder RM. Status of physiology education in US Doctor of Pharmacy programs. Adv Physiol Educ. 2016; 40(4):501-508.

4. Nazar H, Obara I, Paterson A, Nazar Z, Portlock J, Husband A. A consensus approach to investigate undergraduate pharmacy students' experience of interprofessional education. Am J Pharm Educ. 2017; 81(2):Article 26.

5. Pedrami F, Asenso P, Devi S. Using text analytics of AJPE article titles to reveal trends in pharmacy education over the past two decades. Am J Pharm Educ. 2016; 80 (6): Article 104.

6. Chan WC, $\mathrm{Ng} \mathrm{CH}$, Yiu BK, Liu CY, Ip CM, Siu HH, et al. A survey on the preference for continuing professional dental education amongst general dental practitioners who attended the 26th Asia Pacific Dental Congress. Eur J Dent Educ 2006; (10): 210-6

7. Bonwell C Eison J. Active Learning: Creating Excitement in the Classroom. ASHE-ERIC Higher Education Report. Washington, DC: School of Education and Human Development, George Washington University. 1991.

8. Freeman S, Eddy SL, McDonough M, Smith MK, Okoroafor N, Jordt H, Wenderoth MP. Active learning increases student performance in science, engineering, and mathematics. Proc Natl Acad Sci USA, 2014; 111: 8410-8415.

9. Barrows HS. A taxonomy of problem-based learning methods. Med Educ, 1986 (20): 481-486.

10. Thistlethwaite JE, Davies D, Ekeocha S, Kidd JM, MacDougall C, Matthews P, Purkis J, Clay D. The effectiveness of case-based learning in health professional education. A BEME systematic review: BEME Guide No. 23. Med Teach 2012; (34): e421-e444.

11. Albanese M. Problem-based learning: why curricula are likely to show little effect on knowledge and clinical skills. Med Educ; 2000 (34): $729-738$.

12. Vernon DT, Blake RL. Does problem-based learning work? A metaanalysis of evaluative research. Acad Med 1993; (68): 550-563.

13. Blewett EL, Kisamore JL. Evaluation of an interactive, case-based review session in teaching medical microbiology. BMC Med Educ 2009 ; (9): 56.

14. Gemmell HA. Comparison of teaching orthopaedics using an integrated case-based curriculum and a conventional curriculum: A preliminary study. Clin Chiropr 2007; (10): 36-42.

15. Moore GT, Block SD, Style CB, Mitchell R. The influence of the New Pathway curriculum on Harvard medical students. Acad Med 1994; (69): $983-989$.

16. Brauer DG, Ferguson KJ. The integrated curriculum in medical education: AMEE Guide No.96. Med Teach 2015; (37): 312-22.

17. Kirschner PA, Sweller J, Clark RE. Why minimal guidance during instruction does not work: An analysis of the failure of constructivist, discovery, problembased, experiential, and inquiry-based teaching. Educ Psychol 2006; (41): 75-86.

18. Mehta NB, Hull AL, Young JB, et al. Just imagine: new paradigms for medical education. Acad Med. 2013; (88):1418-1423.

19. Baeten M, Kyndt E, Struyven K. Using studentcentred learning environments to stimulate deep approaches to learning: factors encouraging or discouraging their effectiveness. Educ Res Rev. 2010;5 (3):243-260.

20. Entwistle NJ. Approaches to learning and perceptions of the learning environment: introduction to the special issue. High Educ. 1991; 22(3):201-204.

21. Katlin R. Integration from the Student Perspective: Constructing Meaning. Center of the Learning and Teaching of Elementary Subjects; 1992.

22. Schmidt HG, Rotgans JI, Yew EH. The process of problem-based learning: what works and why. Med Educ; 2011 (45): 792-806.

23. Trowler V. Student Engagement Literature Review. York, UK: Higher Education Academy; 2010, p. 1-15.

24. Hmelo-Silver CE, Duncan RG, Chinn CA. Scaffolding and achievement in problem-based and inquiry learning: a response to Kirschner, Sweller, and Clark (2006) Educational Psychologist. 2007 Apr 26;42 (2):99-107.

25. White CB, Gruppen LD, Fantone JC. Self-regulated learning in medical education. Tim S, editor. Underst. Med. Educ. [Internet]. John Wiley \& Sons, Ltd; 2013. Cited 2018 Mar 5 201-211.

26. Joshi AS, Ganjiwale JD, Varma J, et al. Qualitative assessment of learning strategies among medical students using focus group discussions and indepth interviews. Int J Appl Basic Med Res. 2017; (7):S33-S37.

27. Harden RM. The integration ladder: a tool for curriculum planning and evaluation. Med Educ. 2000 Jul; 34(7):551-557.

28. Lisa SL, Lois SS, and Sanjay D. Hidden Curricula, Ethics, and Professionalism: Optimizing Clinical Learning Environments in Becoming and Being a Physician: A Position Paper of the American College of Physicians. Ann Intern Med. 2018; (168):506-508.

29. Prober CG, Khan S. Medical education re-imagined: a call to action. Acad Med. 2013; (88):1407-1410.

\section{Figures}




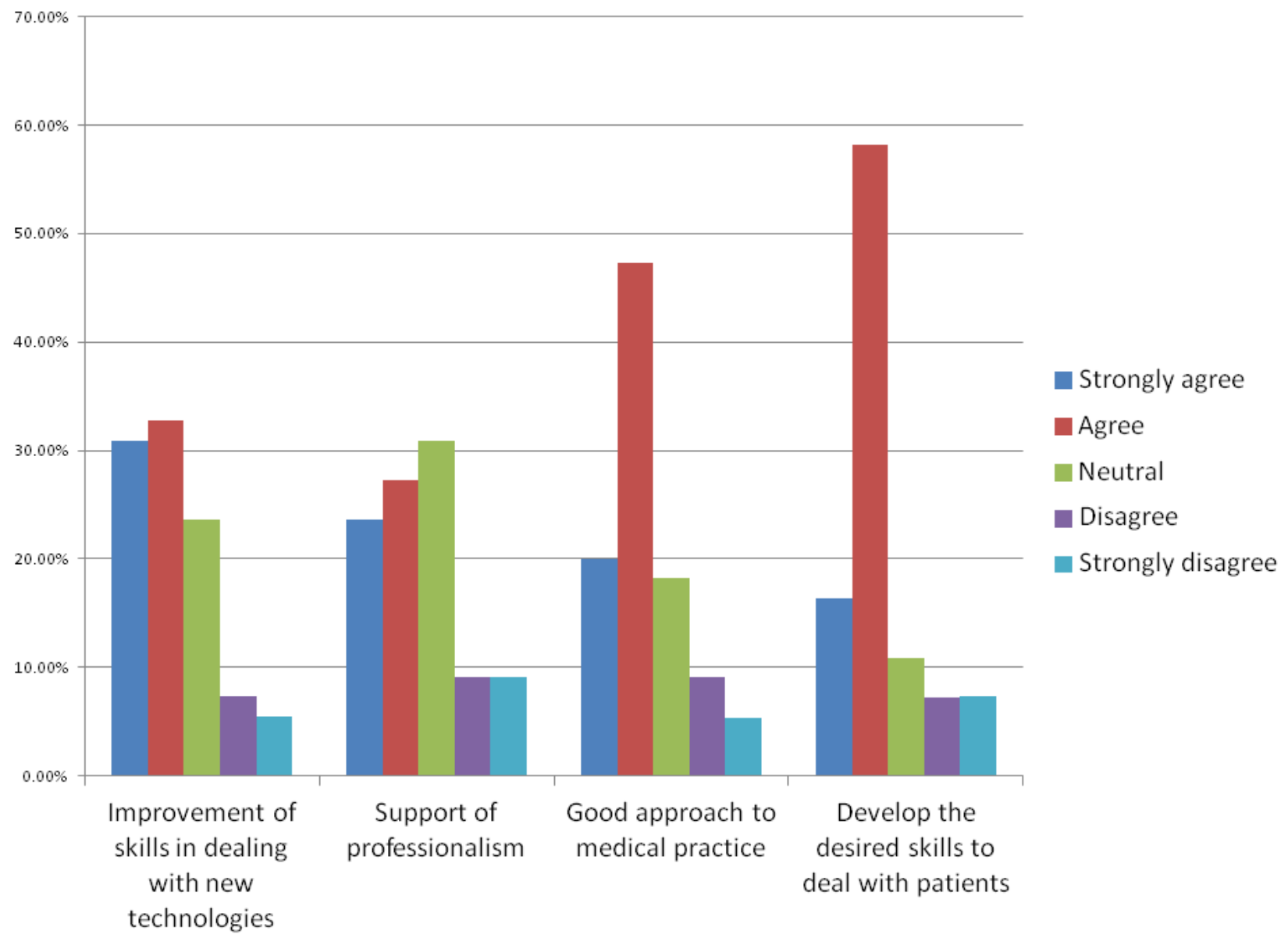

Figure 1

(1A): Percentages (\%) of different degrees of student satisfaction in traditional learning program (A) and integrated learning program (B) (1 B): Percentages of the agreement and disagreement after exclusion of the neutral degree

\section{Supplementary Files}

This is a list of supplementary files associated with this preprint. Click to download.

- Supplementaryfile.docx 